\title{
A copper(II)-selective chelator ameliorates left-ventricular hypertrophy in type 2 diabetic patients: a randomised placebo-controlled study
}

\author{
G. J. S. Cooper • A. A. Young • G. D. Gamble • \\ C. J. Occleshaw • A. M. Dissanayake • B. R. Cowan • \\ D. H. Brunton • J. R. Baker • A. R. J. Phillips • \\ C. M. Frampton • S. D. Poppitt • R. N. Doughty
}

Received: 17 November 2008 / Accepted: 11 December 2008 / Published online: 27 January 2009

(C) Springer-Verlag 2009

\begin{abstract}
Aims/hypothesis $\mathrm{Cu}$ (II)-selective chelation with trientine ameliorates cardiovascular and renal disease in a model of diabetes in rats. Here, we tested the hypothesis that $\mathrm{Cu}$ (II)selective chelation might improve left ventricular hypertrophy (LVH) in type 2 diabetic patients.

Methods We performed a 12 month randomised placebocontrolled study of the effects of treatment with the $\mathrm{Cu}$ (II)-selective chelator trientine (triethylenetetramine dihydrochloride, $600 \mathrm{mg}$ given orally twice daily) on LVH in diabetic patients ( $n=15$ /group at baseline) in an outpatient setting wherein participants, caregivers and those assessing outcomes were blinded to group assignment. Using MRI, we measured left ventricular variables at baseline, and at months 6 and 12. The change from baseline in left ventricular mass indexed to body surface area $\left(\mathrm{LVM}_{\mathrm{bsa}}\right)$ was the primary endpoint variable.
\end{abstract}

G. J. S. Cooper $(\bowtie) \cdot$ D. H. Brunton · A. R. J. Phillips •

S. D. Poppitt

Level 4, School of Biological Sciences, Faculty of Science,

University of Auckland,

Private Bag 92019,

Auckland 1142, New Zealand

e-mail: g.cooper@auckland.ac.nz

G. J. S. Cooper · A. R. J. Phillips

Maurice Wilkins Centre for Molecular Biodiscovery,

Faculty of Science, University of Auckland,

Auckland, New Zealand

G. J. S. Cooper · G. D. Gamble • B. R. Cowan • S. D. Poppitt •

R. N. Doughty

Department of Medicine, School of Medicine,

Faculty of Medical and Health Sciences, University of Auckland,

Auckland, New Zealand
Results Diabetic patients had LVH with preserved ejection fraction at baseline. Trientine treatment decreased $\mathrm{LVM}_{\mathrm{bsa}}$ by $5.0 \pm 7.2 \mathrm{~g} / \mathrm{m}^{2}($ mean $\pm \mathrm{SD})$ at month 6 (when 14 trientine-treated and 14 placebo-treated participants were analysed; $p=0.0056$ compared with placebo) and by $10.6 \pm$ $7.6 \mathrm{~g} / \mathrm{m}^{2}$ at month 12 (when nine trientine-treated and 13 placebo-treated participants were analysed; $p=0.0088$ ), whereas $L \mathrm{MM}_{\mathrm{bsa}}$ was unchanged by placebo treatment. In a multiple-regression model that explained $\sim 75 \%$ of variation $\left(R^{2}=0.748, p=0.001\right)$, cumulative urinary $\mathrm{Cu}$ excretion over 12 months was positively associated with trientine-evoked decreases in $\mathrm{LVM}_{\mathrm{bsa}}$.

Conclusions/interpretation $\mathrm{Cu}(\mathrm{II})$-selective chelation merits further exploration as a potential pharmacotherapy for diabetic heart disease.
A. A. Young • B. R. Cowan

Department of Anatomy with Radiology, School of Medicine, Faculty of Medical and Health Sciences, University of Auckland, Auckland, New Zealand

\section{J. Occleshaw}

Department of Cardiology, Greenlane Hospital,

Auckland, New Zealand

A. M. Dissanayake $\cdot$ J. R. Baker

South Auckland Diabetes Service, Middlemore Hospital,

Otahuhu, New Zealand

C. M. Frampton

Department of Medicine, Christchurch Clinical School,

University of Otago,

Christchurch, New Zealand 
Trial registration: Australian New Zealand Clinical Trials Registry ACTRN 12609000053224

Funding: The Endocore Research Trust; Lottery Health New Zealand; the Maurice and Phyllis Paykel Trust; the Foundation of Research, Science and Technology (New Zealand); the Health Research Council of New Zealand; the Ministry of Education (New Zealand) through the Maurice Wilkins Centre for Molecular Biodiscovery; and the Protemix Corporation.

Keywords Cardiac magnetic resonance imaging - Copper . Diabetic cardiomyopathy · Left-ventricular hypertrophy .

Oral copper chelation · Triethylenetetramine

$\begin{array}{ll}\text { Abbreviations } \\ \text { LV } & \text { left ventricle } \\ \text { LVH } & \text { left ventricular hypertrophy } \\ \text { LVM } & \text { left ventricular mass } \\ \text { LVM }_{\text {bsa }} & \text { left ventricular mass indexed to body surface area }\end{array}$

\section{Introduction}

Heart disease in diabetes is characterised by left ventricular hypertrophy $(\mathrm{LVH})[1,2]$ and increased rates of heart failure $[3,4]$. We recently characterised a hyperglycaemiadriven pathogenic abnormality of copper homeostasis in type 2 diabetic patients and showed that their $\mathrm{Cu}$ balance can be improved by treatment with trientine [5], a drug that is also sometimes used as a treatment for Wilson's disease [6]. Trientine also improves LVH, left ventricle (LV) function [7] and aortic structure [8] in rat models of diabetes, in which it also reverses cardiac fibrosis without altering blood glucose or BP. Chelatable $\mathrm{Cu}$ is increased in the hearts of rat models of diabetes, and elevated extracellular $\mathrm{Cu}$ might be implicated in the mechanism of cardiovascular damage in diabetes [7,8]. Trientine treatment also normalised renal fibrosis, albuminuria, and pathogenic TGF- $\beta$ activation in the kidneys of a rodent model of diabetic nephropathy [9].

Here, we tested the hypothesis that trientine treatment might ameliorate LVH in type 2 diabetic patients. We now report results from a 12 month prospective, randomised placebo-controlled study of the effect of trientine treatment on LVH in diabetic patients conducted in an outpatient setting wherein participants, caregivers and those assessing outcomes were blinded to group assignment.

\section{Methods}

Design This was a randomised placebo-controlled study that examined the effects of 12 months of oral trientine (triethylenetetramine dihydrochloride, $600 \mathrm{mg}$ twice daily orally) or placebo treatment in 15 patients/group at baseline who had type 2 diabetes with $\mathrm{LVH}$ as determined by echocardiography [10] and cardiac MRI [11]. Change in left ventricular mass indexed to body surface area $\left(\mathrm{LVM}_{\mathrm{bsa}}\right)$ as determined by cardiac MRI [11] was the main endpoint. Written informed consent was obtained from all patients prior to enrolment. Institutional ethics and New Zealand regulatory committees approved the research protocol and experimental use of trientine in this patient population, and the study conformed to the Declaration of Helsinki [12]. Patients continued on their usual medications throughout and study medication was additional. We monitored urinary $\mathrm{Cu}$ excretion as a measure of drug action, and plasma $\mathrm{Cu}$ and relevant haematological variables to check for possible $\mathrm{Cu}$ deficiency.

Patients Criteria for patient inclusion were: age between 30 and 70 years; known type 2 diabetes; $\mathrm{HbA}_{1 \mathrm{c}}>7.0 \%$ at enrolment; normal electrocardiogram (exhibiting sinus rhythm, normal PR interval, T wave and QRS configuration, and an isoelectric ST segment); abnormal diastolic filling as demonstrated by mitral inflow Doppler with preload reduction [10] (no patient with normal mitral filling proceeded to randomisation); LV ejection fraction $\geq 45 \%$ by echocardiography, with evidence of diastolic dysfunction but no regional wall-motion abnormalities [10]; and no new medication for 6 months prior to randomisation with no change of $\beta$-blocker dose during that period. Female patients were postmenopausal, surgically sterile, or non-lactating and non-pregnant and using adequate contraception.

Patients were ineligible if they failed to meet the inclusion criteria or had one or more of the following: morbid obesity $\left(\mathrm{BMI} \geq 45 \mathrm{~kg} / \mathrm{m}^{2}\right)$; type 1 diabetes; history or evidence of diabetic retinopathy and/or diabetic nephropathy (serum creatinine $>50 \mu \mathrm{mol} / 1$ and/or urinary albumin $>300 \mathrm{mg} / \mathrm{l}$ ); autonomic neuropathy; significant cardiac valvular disease; LV wall motion abnormality by echocardiography; history of significant malabsorption; multiple drug allergies; use or misuse of substances of abuse; evidence of abnormal electrolyte homeostasis or renal, hepatic or thyroid function; or standard contraindications to MRI.

Conduct Trial performance was independently monitored. Before randomisation, patients entered a 4 week run-in period taking two placebo capsules twice daily when they were blinded as to treatment, during which $\geq 90 \%$ compliance was required for progression. Patients meeting inclusion criteria were randomised to receive trientine (two $300 \mathrm{mg}$ capsules twice daily; Anstead International, Basildon, Essex, UK) before breakfast and the evening meal, or identical placebo capsules. Treatment assignment was performed centrally using variable block sizes to 
ensure balance throughout trial recruitment and numbered drug packs were prepared and dispensed sequentially to randomised patients. Systemic $\mathrm{Cu}$ status was monitored throughout by an every other month (two-monthly) determination of plasma $\mathrm{Cu}$ and haematological variables relevant to the detection and monitoring of systemic $\mathrm{Cu}$ and $\mathrm{Fe}$ deficiency, including total blood haemoglobin concentration, and mean erythrocyte volume and erythrocyte haemoglobin content [13].

Cardiac MRI Left ventricular mass (LVM) was determined by cardiac MRI performed in the supine position at a single centre with the same 1.5 T scanner (Siemens Vision; Siemens AG, Munich, Germany) using a phased-array surface coil [11]. Three scout scans were obtained to define the long and short axes of the LV. Cine-turbo fast low-angle shot MR images were obtained in eight or nine short-axis slices that were equally spaced from apex to base and in three long-axis slices at equal angular intervals around the central axis of the LV (scan variables were: slice thickness, $8 \mathrm{~mm}$; in-plane resolution, $\sim 1 \mathrm{~mm} /$ pixel; temporal resolution, 30-50 ms depending on heart rate; and echo time/ repetition time, $4.0 / 9.0 \mathrm{~ms}$ ).

Patients undertook approximately $15 \mathrm{~s}$ breath-holds during the scans to eliminate respiratory motion artefacts. View sharing was used to reconstruct 13-27 time frames per cardiac cycle, depending on heart rate. Prospectively gated gradient echo images were acquired in six short-axis and three long-axis slices with the use of a segmented k-space pulse sequence (repetition time, $8 \mathrm{~ms}$; echo time, $5 \mathrm{~ms}$; flip angle, $10^{\circ}$; field of view, $280-350 \mathrm{~mm}$ ) with view sharing (11-19 frames/slice). Each slice was obtained during a breath-hold of 15-19 heartbeats. The short-axis slices spanned the LV from apex to base with a slice thickness of $8 \mathrm{~mm}$ and inter-slice gap of 2-6 mm. Long-axis slices were positioned at equal $60^{\circ}$ intervals about the LV long axis.

All measurements were performed by a single member of the research team who was blinded to group assignment. LVM and LV volumes were calculated using guide-point modelling, which generates precise and accurate estimations of mass and volume [11]. A three-dimensional mathematical model of the LV was interactively fitted simultaneously to the epicardial and endocardial boundaries of the wall in each slice. Volumes were calculated up to but not beyond the mitral valve plane as defined by that through the hinge points of the mitral valve leaflets. Volume and mass were then calculated from the model by numerical integration $($ mass $=$ wall volume $\times 1.05 \mathrm{~g} / \mathrm{ml})$, and ejection fraction and $\mathrm{LVM}_{\mathrm{bsa}}$ were derived, where body surface area (in $\mathrm{m}^{2}$ ) was calculated using the following formula (with weight in $\mathrm{kg}$ and height in $\mathrm{cm}$ ): body surface area= $($ weight $\times 0.425) \times($ height $\times 0.725) \times 0.007184$ [14]
Statistical analysis Outcome analyses were conducted by intention-to-treat, using a maximum-likelihood approach to impute missing-at-random data within a linear mixedeffects model [15], and marginal least squares adjustedmeans were determined. Changes from baseline were compared between treatment groups in the mixed model with baseline values entered as a covariate. Since there were only two groups in the main effect and no interaction effect, no post hoc procedures were employed. In additional analysis, the influence of clinically important differences between the treatment groups at baseline was considered by adjusting for them as covariates in an additional model. The effect of treatment on categorical variables was tested using the Mantel-Haenzel test (SAS v8.01; SAS Institute, Cary, NC, USA). Pearson's correlation coefficients were calculated between individual baseline variables or total 12 month urine $\mathrm{Cu}$ excretion, and change in $\mathrm{LVM}_{\mathrm{bsa}}$ from baseline to 12 months: a model predicting this variable was then constructed by initially adding all those predictive variables with Pearson's coefficients whose corresponding $p$ values were $\leq 0.20$, into a forward, stepwise multiple regression model, with $\alpha=0.25$ for entry and $\alpha=0.10$ for leaving (SPSS 14.0; SPSS, Chicago, IL, USA). Other statistical tests were performed using SPlus 7.0 (Insightful Corporation, Seattle, WA, USA). All $p$ values were calculated from two-tailed tests and those $<0.05$ were considered significant.

\section{Results}

Group characteristics Treatment and control groups were well matched for baseline characteristics including age; $\mathrm{BMI}$; duration of diabetes; $\mathrm{HbA}_{1 \mathrm{c}}$; creatinine clearance; haematological variables; frequency of glucose-lowering and antihypertensive drug treatments; and serum and urinary $\mathrm{Cu}$ values (Table 1). Most measured cardiovascular variables were also matched between groups at baseline, including systolic and diastolic BP, LVM, LVM $\mathrm{bsa}_{\mathrm{ba}}$, and measures of LV volume (Table 1). Baseline ejection fraction in the trientine-treated group was significantly lower than that in the placebo-treated group.

Patient disposition during the trial is illustrated in Fig. 1. Eight patients discontinued study drug prematurely through to month 12 under the following circumstances: one had a fatal MI; three discontinued drug because of adverse events, two of whom were receiving placebo treatment; and four discontinued because of a combination of 'unable', 'unwilling' or 'other' non-specified reasons. Two patients stopped treatment but attended clinic visits through to month 12 for efficacy and safety measurements, and one continued treatment but did not consent to cardiac MRI at 
Table 1 Pertinent baseline characteristics

\begin{tabular}{|c|c|c|}
\hline Variable & Placebo & Triethylenetetramine \\
\hline Age (years) & $53(43-64)$ & $52(33-69)$ \\
\hline Male sex, $n(\%)$ & $10(68)$ & $11(73)$ \\
\hline BMI $\left(\mathrm{kg} / \mathrm{m}^{2}\right)$ & $31.9 \pm 4.9$ & $34.3 \pm 5.1$ \\
\hline Duration of diabetes (years) & $11(1-24)$ & $8(1-21)$ \\
\hline Creatinine clearance $(\mathrm{ml} / \mathrm{min})$ & $80.1 \pm 19.4$ & $77.4 \pm 21.0$ \\
\hline Serum magnesium $(\mu \mathrm{mol} / \mathrm{l})$ & $783 \pm 45$ & $809 \pm 81$ \\
\hline Serum albumin $(g / 1)$ & $40.9 \pm 1.6$ & $42.3 \pm 2.2$ \\
\hline $\mathrm{HbA}_{1 \mathrm{c}}>8 \%, n(\%)$ & $13(87)$ & $13(87)$ \\
\hline $\mathrm{HbA}_{1 \mathrm{c}}(\%)$ & $9.3 \pm 1.3$ & $9.4 \pm 2.0$ \\
\hline $\begin{array}{l}\text { Serum EC-SOD activity } \\
\text { (units/l) }\end{array}$ & $38.4 \pm 47.6$ & $24.5 \pm 32.3$ \\
\hline Serum $\mathrm{Cu}(\mu \mathrm{mol} / \mathrm{l})$ & $17.8 \pm 3.4$ & $18.7 \pm 3.8$ \\
\hline $\begin{array}{l}\text { Urinary } \mathrm{Cu} \text { excretion } \\
(\mu \mathrm{mol} / \mathrm{day})\end{array}$ & $0.44 \pm 0.48$ & $0.37 \pm 0.36$ \\
\hline Serum iron $(\mu \mathrm{mol} / 1)$ & $12.5 \pm 3.2$ & $14.4 \pm 2.7$ \\
\hline Serum IBC $(\mu \mathrm{mol} / \mathrm{l})$ & $52.7 \pm 9.0$ & $57.0 \pm 6.7$ \\
\hline Serum ferritin $(\mu \mathrm{g} / \mathrm{l})$ & $241 \pm 172$ & $207 \pm 168$ \\
\hline Serum zinc $(\mu \mathrm{mol} / \mathrm{l})$ & $12.7 \pm 1.3$ & $12.7 \pm 1.9$ \\
\hline Haemoglobin (g/l) & $143.8 \pm 9.7$ & $146.0 \pm 14.9$ \\
\hline Packed cell volume (\%) & $0.42 \pm 0.03$ & $0.43 \pm 0.04$ \\
\hline Mean cell volume (fl) & $87.4 \pm 3.9$ & $85.9 \pm 3.9$ \\
\hline Erythrocyte count $\left(\times 10^{12} / 1\right)$ & $4.83 \pm 0.35$ & $4.99 \pm 0.60$ \\
\hline Receiving a sulfonylurea, $n(\%)$ & $7(47)$ & $11(73)$ \\
\hline Receiving metformin, $n(\%)$ & $14(93)$ & $14(93)$ \\
\hline Receiving insulin, $n(\%)$ & $9(60)$ & $10(67)$ \\
\hline $\begin{array}{l}\text { Receiving a diuretic agent, } \\
n(\%)\end{array}$ & $3(20)$ & $4(27)$ \\
\hline $\begin{array}{l}\text { Receiving an ACEI or ARB, } \\
n(\%)\end{array}$ & $12(80)$ & $11(73)$ \\
\hline Receiving a $\beta$-blocker, $n(\%)$ & $2(13)$ & $4(27)$ \\
\hline Systolic BP (mmHg) & $134.3 \pm 17.8$ & $135.3 \pm 15.9$ \\
\hline Diastolic BP (mmHg) & $84.9 \pm 8.0$ & $83.7 \pm 7.8$ \\
\hline LVM (g) & $202.2 \pm 53.1$ & $210.7 \pm 48.9[14]$ \\
\hline $\operatorname{LVM}_{\mathrm{bsa}}\left(\mathrm{g} / \mathrm{m}^{2}\right)$ & $99.5 \pm 19.9$ & $101.3 \pm 21.2[14]$ \\
\hline $\operatorname{EDV}_{\text {bsa }}\left(\mathrm{ml} / \mathrm{m}^{2}\right)$ & $60.4 \pm 12.7$ & $58.0 \pm 9.8[14]$ \\
\hline $\operatorname{ESV}_{\mathrm{bsa}}\left(\mathrm{ml} / \mathrm{m}^{2}\right)$ & $17.7 \pm 6.6$ & $20.4 \pm 5.9[14]$ \\
\hline Ejection fraction (\%) & $71.1 \pm 6.3$ & $65.2 \pm 5.9[14]^{*}$ \\
\hline$E / E^{\prime}$ & $8.85 \pm 1.97$ & $8.87 \pm 2.01[12]$ \\
\hline BNP (pmol/l) & $6.1 \pm 3.1[11]$ & $12.6 \pm 20.9[11]$ \\
\hline
\end{tabular}

Data with \pm values are means $\pm \mathrm{SD}$; age and duration are median (range); $[n]$ if less than $n=15$ per group

${ }^{*} p=0.015$, all other differences were not significant

ACEI, ACE inhibitor; ARB, angiotensin II receptor blocker; BNP, Btype natriuretic peptide; $E D V_{b s a}$, end diastolic volume indexed to body surface area; EC-SOD, extracellular superoxide dismutase; $E / E^{\prime}$, trans-mitral flow velocity/mitral annular velocity; $\mathrm{ESV}_{\mathrm{bsa}}$, end systolic volume indexed to body surface area; IBC, iron binding capacity

month 12. There were no significant differences in rates of adverse events or serious adverse events between trientineand placebo-treated groups.

Effects of drug treatment on the main endpoint variable The change in $\mathrm{LVM}_{\mathrm{bsa}}$ from baseline to month 6 was $3.1 \pm$

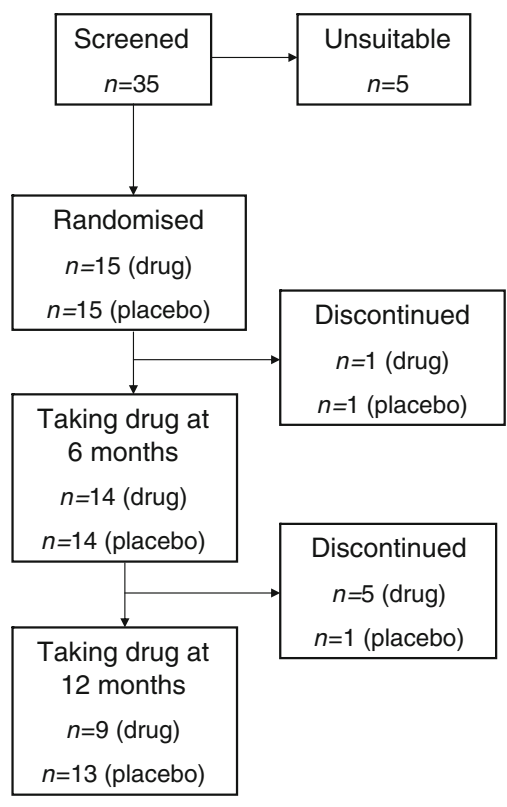

Fig. 1 Flow chart illustrating changes in the patient population during the 12-month course of the study

$7.0 \mathrm{~g} / \mathrm{m}^{2}$ in the placebo-treated group and $-5.0 \pm 7.2 \mathrm{~g} / \mathrm{m}^{2}$ in the trientine-treated group $(p=0.0056)$. The corresponding changes in $\mathrm{LVM}_{\mathrm{bsa}}$ from baseline at month 12 were $-0.1 \pm$ $9.8 \mathrm{~g} / \mathrm{m}^{2}$ in the placebo-treated group and $-10.6 \pm 7.6 \mathrm{~g} / \mathrm{m}^{2}$ in the trientine-treated group $(p=0.0088)$.

Effects of drug treatment on $L V M_{b s a}$ Mean $\operatorname{LVM}_{\mathrm{bsa}}$ decreased significantly in trientine-treated patients (Fig. 2a), from $101.3 \pm 21.2 \mathrm{~g} / \mathrm{m}^{2}($ mean $\pm \mathrm{SD})$ at baseline to $96.3 \pm 22.3 \mathrm{~g} / \mathrm{m}^{2}$ at month 6 ( $p=0.0006$ compared with placebo) and $91.4 \pm 13.5 \mathrm{~g} / \mathrm{m}^{2}$ at month $12(p=0.011)$. In contrast, $\mathrm{LVM}_{\mathrm{bsa}}$ in placebo-treated individuals was unchanged at month 6 and month 12 .

Other cardiovascular variables Trientine did not cause significant time-dependent or inter-group changes in other variables of cardiovascular significance, including the following (results not shown): systolic or diastolic BP; end diastolic volume or end diastolic volume indexed to body surface area; end systolic volume or end systolic volume indexed to body surface area; ejection fraction; trans-mitral flow velocity/mitral annular velocity; or plasma concentrations of B-type natriuretic peptide.

Drug exposure Between baseline and month 6, the mean daily exposure to study drug was comparable between groups (3.6 vs 3.4 capsules per day), and represented $90 \%$ and $85 \%$ compliance for drug- and placebo-treatment, respectively. Between month 6 and month 12, the mean daily exposure to study drug was not significantly different between treatment groups (3.6 capsules per day). 
a

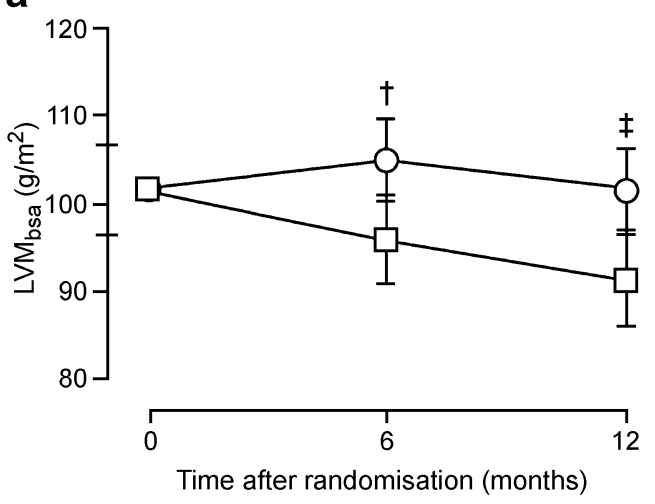

b

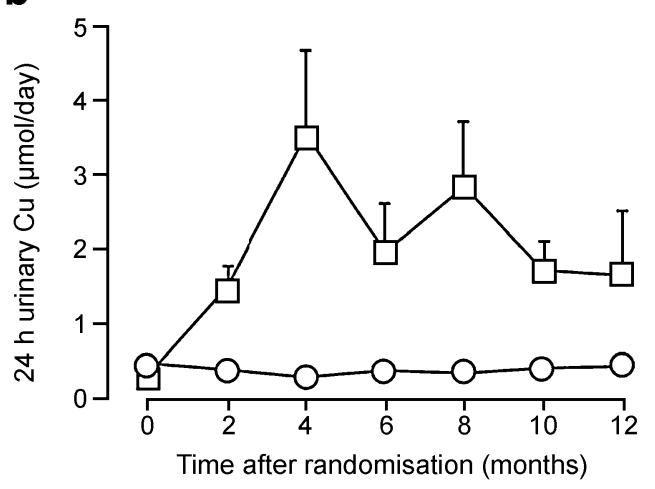

C

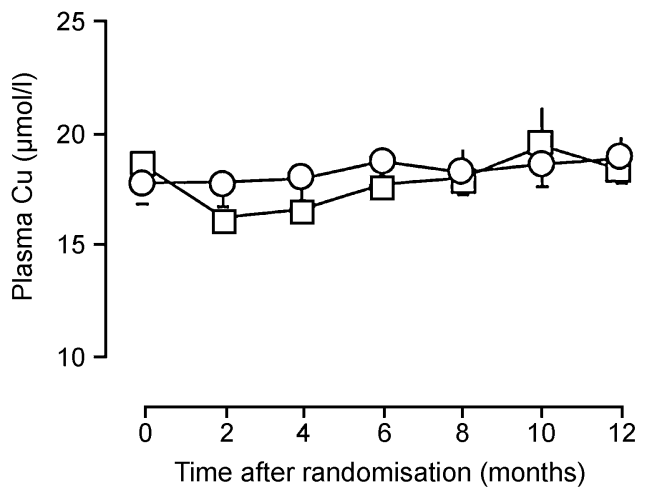

Fig. 2 Time-dependent responses of LVMbsa (a), urinary $\mathrm{Cu}(\mathbf{b})$ and plasma $\mathrm{Cu}$ (c) in trientine-treated (squares; $n=15$ at baseline) or placebo-treated (circles; $n=15$ at baseline) type 2 diabetic patients. a ${ }^{\dagger} p=0.0056,{ }^{\star} p=0.0088$ contrast between-group differences in change in $\mathrm{LVM}_{\mathrm{bsa}}$ from baseline. b Exact $p$ values for differences in urinary $\mathrm{Cu}$ at time points were: baseline, $0.34 ; 2$ months, $0.0017 ; 4$ months, 0.0044; 6 months, 0.014 ; 8 months, $0.0028 ; 10$ months, 0.0020 ; and 12 months, 0.13 . c Plasma $\mathrm{Cu}$ concentrations did not differ between groups at any time point. Values are means \pm SEM

Urinary $\mathrm{Cu}$ excretion Figure 2b shows $24 \mathrm{~h}$ urinary $\mathrm{Cu}$ excretion values from baseline at two-monthly intervals until month 12. Trientine treatment increased $24 \mathrm{~h}$ urinary $\mathrm{Cu}$ excretion from a median (range) of $0.30(0.10-2.0)$ $\mu \mathrm{mol} /$ day to a peak of $2.4(0.70-11.0) \mu \mathrm{mol} / \mathrm{day}$ at 4 months. Thereafter, drug-evoked $\mathrm{Cu}$ excretion fell gradually to reach $0.70(0.20-7.6) \mu \mathrm{mol} /$ day at 12 months, when it did not differ significantly from placebo (Table 1 ).
$\mathrm{Cu}$ excretion in the placebo-treated group remained at basal levels throughout (Fig. 2b).

Concomitant medications The frequency of concomitant medications was equivalent between groups at baseline (Table 1). Of particular relevance to the study outcomes, at enrolment 11 of 15 drug-treated patients $(73 \%)$ and 12 of 15 placebo-treated patients $(80 \%)$ were receiving either ACE inhibitors or angiotensin II receptor blockers. Three patients, all in the placebo-treated group, were either started on an ACE inhibitor or had their dose increased one or more times during the study.

Plasma $\mathrm{Cu}$ Systemic $\mathrm{Cu}$ deficiency may be detected by low or falling plasma $\mathrm{Cu}$ concentrations, which may also be used to monitor $\mathrm{Cu}$ deficiency [16]. Severe $\mathrm{Cu}$ deficiency can cause dilated cardiomyopathy and heart failure in experimental animals [17]. To detect any possible tendency towards systemic $\mathrm{Cu}$ deficiency in trientine-treated diabetic patients, we monitored plasma $\mathrm{Cu}$ concentrations and relevant haematological variables two-monthly. Plasma $\mathrm{Cu}$ did not change significantly during the study in either treatment group nor did significant differences develop between these groups (Fig. 2c). There was no evidence that 12 months of trientine treatment caused detectable systemic $\mathrm{Cu}$ deficiency.

Statistical models of change in $L V M_{b s a}$ from baseline to month 12 We performed bivariate analysis to examine the relationship between predictor variables and change in $\mathrm{LVM}_{\mathrm{bsa}}$ between baseline and month 12 (Table 2). Indicated variables were then incorporated into a multivariate regression model predicting the change in $\mathrm{LVM}_{\mathrm{bsa}}$ and a final model was derived (Table 3), in which three indicator variables, serum albumin at baseline, age and cumulative urinary $\mathrm{Cu}$ excretion over 12 months, between them account for $75 \%$ of variation. The cumulative urinary $\mathrm{Cu}$ excretion over 12 months, which was a surrogate for trientine treatment, was related both to $\mathrm{LVM}_{\mathrm{bsa}}$ at months 6 and 12 , and to the rate of decrease in $\mathrm{LVM}_{\mathrm{bsa}}$.

Effects of drug treatment on haematological variables We monitored haematological variables at baseline and at twomonthly intervals thereafter. The following changes in variable values between baseline and 12 months, mean (95\% CI), were significantly different between drug-treated and placebo-treated groups, respectively: haemoglobin, $-10.0(-16.3,-3.9) \mathrm{g} / \mathrm{l}$ compared with $1.4(-3.0,5.9) \mathrm{g} / \mathrm{l}$, ( $p=0.003)$; packed cell volume, $-0.03(-0.05,-0.01)$ compared with $0.01(-0.01,0.02),(p=0.0016)$; erythrocyte number, $-0.25(-0.48,-0.02) \times 10^{12} / 1$ compared with 0.12 $(-0.03,0.26) \times 10^{12} / 1,(p=0.0062)$. In contrast, mean corpuscular volume did not differ. Changes in serum iron, iron 
Table 2 Bivariate correlations between change in $\mathrm{LVM}_{\mathrm{bsa}}$ from baseline to 12 month follow-up and those variables that were included in the initial multivariate regression model

\begin{tabular}{lcc}
\hline Variable & Pearson coefficient & $p$ value $^{\mathrm{a}}$ \\
\hline Age at baseline & 0.40 & 0.06 \\
Systolic BP (seated, at baseline) & 0.37 & 0.08 \\
Systolic BP (standing, at baseline) & 0.40 & 0.06 \\
Diastolic BP (standing, at baseline) & 0.29 & 0.18 \\
Serum albumin at baseline & -0.67 & 0.00 \\
Serum zinc at baseline & -0.47 & 0.03 \\
Serum iron at baseline & -0.35 & 0.10 \\
Serum magnesium at baseline & -0.29 & 0.18 \\
Haemoglobin at baseline & -0.50 & 0.02 \\
Packed cell volume at baseline & -0.48 & 0.02 \\
Erythrocytes at baseline $^{\text {Urinary Cu excretion }}{ }^{\mathrm{b}}$ & -0.37 & 0.09 \\
\hline
\end{tabular}

These variables were selected from an initial group of 30 , the rest of which had $p$ values $>0.20$

${ }^{a}$ Two-tailed

${ }^{\mathrm{b}}$ AUC over 12 month follow-up

binding capacity, ferritin and numbers of white blood cells and platelets between baseline and 12 months did not differ significantly between treatment groups. Thus drug treatment tended to lower haemoglobin concentrations and erythrocyte numbers to a modest extent, in line with some previous reports [6]. Vigilance will be necessary in further studies of trientine treatment in patients at greater risk of haematological impairment, such as those with diabetic nephropathy [18].

\section{Discussion}

This is the first trial to have explored a possible role for a $\mathrm{Cu}(\mathrm{II})$-selective chelator in treating $\mathrm{LVH}$ in diabetic patients. In it, oral trientine caused a significant decrease in $\mathrm{LVM}_{\mathrm{bsa}}$, of $5 \%$ at 6 months and $10 \%$ after 12 months of treatment. Since age-matched normotensive non-diabetic controls typically have an LVM of $\sim 130-150 \mathrm{~g}$, this decrease represented a $\sim 50 \%$ restoration of LVM towards

Table 3 Multivariate regression model predicting change in $\mathrm{LVM}_{\mathrm{bsa}}$ from indicated variables

\begin{tabular}{lcccc}
\hline Variable & $\beta$-coefficient & SE & $t$ & $p$ value \\
\hline Intercept & 26.60 & 3.31 & 0.004 & \\
Serum albumin & -0.60 & 0.58 & -5.04 & $<0.001$ \\
$\quad$ at baseline & & & & \\
Age & +0.43 & 0.18 & 3.50 & 0.003 \\
Urinary $\mathrm{Cu}$ excretion $^{\mathrm{a}}$ & -0.42 & 0.07 & -3.43 & 0.003 \\
\hline
\end{tabular}

For this model, $R^{2}=0.748$, the $\mathrm{SE}$ of the estimate $=5.68$ and $p=0.001$

${ }^{\text {a }}$ Total urinary $\mathrm{Cu}$ excretion over 12 months of treatment was calculated as AUC normal by the end of the treatment period. This outcome, present in nine $(90 \%)$ of treated patients after 12 months of therapy, was achieved without adverse remodelling consequences; in particular, there were no concomitant changes in ejection fraction or measures of LV volume. The reduction in $L \mathrm{MM}_{\mathrm{bsa}}$ could not be explained by changes in BP or glycaemia, or by concomitant therapy with angiotensin inhibition. In a step-wise multiple regression model which explained $\sim 75 \%$ of all variation, factors positively associated with decrease in $\mathrm{LVM}_{\mathrm{bsa}}$ included cumulative urinary $\mathrm{Cu}$ excretion over 12 months, serum albumin at baseline and younger age.

The decrease in $\mathrm{LVM}_{\mathrm{bsa}}$ caused by drug treatment in this study could represent a clinically relevant effect size. For example, Levy estimated from Framingham Heart Study data the risk factor-adjusted relative risk of cardiovascular disease and death for increased LVM estimated by echocardiography in 3,220 people with type 2 diabetes and no clinical evidence of coronary artery disease [19]. Each $50 \mathrm{~g}$ increase in LVM per metre of the individual's height increased the risk of cardiovascular disease in men by $49 \%$ and in women by $57 \%$. The same increase in LVM indexed to height was associated with a $73 \%$ increased risk of cardiovascular death in men and $112 \%$ increased risk in women.

In the current trial, trientine stimulated urinary $\mathrm{Cu}$ excretion, which peaked after 4 months and thereafter declined until it had fallen within the basal range by 12 months, when all but one drug-treated individual excreted $<2 \mu \mathrm{mol} /$ day. There was significant inter-individual variability in $\mathrm{Cu}$ excretion throughout the trial, but in general those who cumulatively excreted more $\mathrm{Cu}$ showed greater rates of decrease in LVM. There was also a trend for those who excreted more $\mathrm{Cu}$ to have a larger LVM at baseline. Thus, there were indications in this trial of relationships between indexes of $\mathrm{Cu}$ metabolism and LVM, consistent with our previous findings in an animal model $[7,8]$. Drug treatment did not change plasma $\mathrm{Cu}$ and so, by that criterion, did not cause systemic $\mathrm{Cu}$ deficiency.

Trientine treatment has been linked to haematological abnormalities such as sideroblastic anaemia [20] and thrombocytopenia [6] in occasional patients under treatment for Wilson's disease, in whom it has also been reported to cause low serum iron without anaemia [21]. Drug-treated patients underwent modest but statistically significant decreases in haemoglobin, packed cell volume and erythrocyte numbers, which might signal an effect of drug treatment to lower $\mathrm{Cu}$ levels in the erythropoietic tissue. The appearance of serum albumin as an independent variable in the multivariate model predicting change in LVM is noteworthy, since this protein serves as a key $\mathrm{Cu}$ selective binding protein in the blood [22] and glycated serum albumin reportedly becomes pro-oxidant in the presence of $\mathrm{Cu}$ [23]. Regulation of $\mathrm{Cu}$ homeostasis is 
disordered in type 2 diabetic patients, who demonstrate elevated rates of urinary $\mathrm{Cu}$ excretion and a tendency to elevated $\mathrm{Cu}$ balance compared with matched controls [5]. Trientine treatment elevates urinary $\mathrm{Cu}$ excretion in Wilson's disease, in which this variable reflects drug action [6]. In a previous study, oral trientine treatment normalised $\mathrm{Cu}$ balance in type 2 diabetic patients, in whom elevated pre-treatment plasma extracellular superoxide dismutase (EC-SOD) levels were strongly correlated with a (plasma $\mathrm{Cu}-\mathrm{HbA}_{1 \mathrm{c}}$ interaction [5] and drug treatment suppressed elevations of EC-SOD [5]. We have proposed that, in conjunction with therapies aimed at decreasing hyperglycaemia and BP, the use of compounds that can normalise systemic $\mathrm{Cu}$ balance, might suppress or reverse the tendency to cardiovascular disease in diabetes.

In summary, we have reported here the results of a study in which we measured the effects of chronic treatment with the $\mathrm{Cu}(\mathrm{II})$-selective chelator, trientine on change in $\mathrm{LVM}_{\mathrm{bsa}}$ in type 2 diabetic patients who had LVH at baseline. Drug treatment significantly lowered $\mathrm{LVM}_{\mathrm{bsa}}$ towards normal without causing adverse remodelling. Effects of the drug on this variable were not explicable by improvements in BP, glycaemic control or changes in concomitant medications. We hypothesise that hyperglycaemia-driven impairment of tissue $\mathrm{Cu}$ homeostasis is a significant mechanism of LV disease in diabetes and that selective $\mathrm{Cu}$ (II) chelation should be further explored as a possible treatment for cardiac disease in diabetes.

Acknowledgements We thank P. J. Scott (Department of Medicine, Faculty of Medical and Health Sciences, University of Auckland) and Professor D. N. Sharpe (The Heart Foundation of New Zealand, Greenlane, Auckland) for their encouragement and helpful discussions with us, and $\mathrm{C}$. Tse for her excellent administrative and other contributions to this work. G. J. S. Cooper acknowledges programme support from the Foundation of Research, Science and Technology (New Zealand), the Health Research Council of New Zealand and the Ministry of Education (New Zealand) through the Maurice Wilkins Centre for Molecular Biodiscovery.

Duality of interest G. J. S. Cooper, G. D. Gamble, C. M. Frampton, J. R. Baker, A. M. Dissanayake, A. R. J. Phillips and S. D. Poppitt disclose associations with the Protemix Corporation (Auckland, New Zealand). All others authors declare that there is no duality of interest associated with this manuscript.

\section{References}

1. Devereux RB, Roman MJ, Paranicas M et al (2000) Impact of diabetes on cardiac structure and function: The Strong Heart Study. Circulation 101:2271-2276

2. Galderisi M, Anderson KM, Wilson PF, Levy D (1991) Echocardiographic evidence for the existence of a distinct diabetic cardiomyopathy (The Framingham Heart Study). Am J Cardiol 68:85-89
3. Struthers AD, Morris AD (2002) Screening for and treating leftventricular abnormalities in diabetes mellitus: a new way of reducing cardiac deaths. Lancet 359:1430-1432

4. Mak KH, Topol EJ (2000) Emerging concepts in the management of acute MI in patients with diabetes mellitus. J Am Coll Cardiol 35:563-568

5. Cooper GJS, Chan YK, Dissanayake et al (2005) Demonstration of a hyperglycemia-driven pathogenic abnormality of copper homeostasis in diabetes and its reversibility by selective chelation. Quantitative comparisons between the biology of copper and of eight other nutritionally-essential elements in normal and diabetic individuals. Diabetes 54:1468-1476

6. Siegemund R, Lößner J, Günther K, Siegemund R, Kühn HJ, Bachmann H (1991) Mode of action of triethylenetetramine dihydrochloride on copper metabolism in Wilson's disease. Acta Neurol Scand 83:364-366

7. Cooper GJS, Phillips ARJ, Choong SY et al (2004) Regeneration of the heart in diabetes by selective copper chelation. Diabetes 53:2501-2508

8. Gong D, Lu J, Chen X et al (2006) Molecular changes evoked by triethylenetetramine (TETA) treatment in the extracellular matrix of the heart and aorta in diabetic rats. Mol Pharmacol 70:20452051

9. Gong D, Lu J, Chen X et al (2008) A copper(II)-selective chelator ameliorates diabetes-evoked renal fibrosis and albuminuria, and suppresses pathogenic TGF- $\beta$ activation in the kidneys of rats used as a model of diabetes. Diabetologia 51:1741-1751

10. Doughty RN, Whalley GA, Walsh HA et al (2004) Effects of carvedilol on left ventricular remodeling after acute myocardial infarction: the CAPRICORN Echo Substudy. Circulation 109: 201-206

11. Young AA, Cowan BR, Thrupp SF, Hedley WJ, Dell'Italia LJ (2000) Left ventricular mass and volume: fast calculation with guide-point modeling on MR images. Radiol 216:597602

12. World Medical Association Declaration of Helsinki (1997) Recommendations guiding physicians in biomedical research involving human subjects. Cardiovasc Res 35:2-3

13. Reeves PG, Ralston NV, Idso JP, Lukaski HC (2004) Contrasting and cooperative effects of copper and iron deficiencies in male rats fed different concentrations of manganese and different sources of sulfur amino acids in an AIN-93G-based diet. J Nutr 134:416-425

14. DuBois D, DuBois EF (1916) A formula to estimate the approximate surface area if height and weight be known. Arch Intern Med 17:863-871

15. Little RJ, Rubin DB (1987) Statistical analysis with missing data. New York, Wiley

16. Panel on Micronutrients, Subcommittees on Upper Reference Levels of Nutrients and of Interpretation and Use of Dietary Reference Intakes, and the Standing Committee on the Scientific Evaluation of Dietary Reference Intakes, Institute of Medicine (2001) Dietary reference intakes for vitamin A, vitamin K, arsenic, boron, chromium, copper, iodine, iron, manganese, molybdenum, nickel, silicon, vanadium, and zinc. Washington, DC, National Academy of Sciences

17. Elsherif L, Wang L, Saari JT, Kang YJ (2005) Regression of dietary copper restriction-induced cardiomyopathy by copper repletion in mice. J Nutr 134:855-860

18. Bosman DR, Winkler AS, Marsden JT, Macdougall IC, Watkins PJ (2001) Anemia with erythropoietin deficiency occurs early in diabetic nephropathy. Diabetes Care 24:495-499

19. Levy D, Garrison RJ, Savage DD, Kannel WB, Castelli WP (1990) Prognostic implications of echocardiographically determined left ventricular mass in the Framingham Heart Study. N Engl J Med 322:1561-1566 
20. Condamine L, Hermine O, Alvin P, Levine M, Rey C, Courtecuisse V (1993) Acquired sideroblastic anaemia during treatment of Wilson's disease with triethylene tetramine dihydrochloride. Br J Haematol 83:166-168

21. Morita J, Yoshino M, Watari H et al (1992) Wilson's disease treatment by triethylene tetramine dihydrochloride (trientine,
2HCl): long-term observation. Dev Pharmacol Therap $19: 6-9$

22. Linder MC (1991) Biochemistry of copper. New York, Plenum

23. Bourdon E, Loreau N, Blache D (1999) Glucose and free radicals impair the antioxidant properties of serum albumin. FASEB $\mathrm{J}$ $13: 233-244$ 